\title{
Difficulty and Obstacle in the Management of an Tracheoesophageal Fistula by Accidental Inhalation of a Foreign Body (Chicken Bone), in a 16-month-old Infant at the Amissa Bongo Regional Hospital Center in Franceville
}

\section{Ngakani Offobo Silvère ${ }^{1 *}$, Aseke Kundulunga Jean Albert ${ }^{2}$, Nyamatsiengui Hilaire $^{3}$ and François Ondo Ndong ${ }^{4}$}

${ }^{1}$ General Surgery Department, Amissa BONGO Regional Hospital, Center of Franceville, Gabon

${ }^{2}$ Radiology Department, Amissa BONGO Regional Hospital, Center of Franceville, Gabon ${ }^{3}$ Surgical Department, Military Hospital of AKANDA, Gabon

${ }^{4}$ Centre Hospitalier, Universitaire Libreville, Gabon

*Corresponding Author: Ngakani Offobo Silvère, General Surgery Department, Amissa BONGO Regional Hospital, Center of Franceville, Gabon.

DOI: 10.31080/ASMS.2022.06.1190
Received: December 08, 2021

Published: February 11, 2022

(C) All rights are reserved by Ngakani Offobo

Silvère., et al.

\begin{abstract}
The inhalation of foreign bodies is a frequent, poorly listed and multifactorial situation. It may be accidental or voluntary. Through this observation in 16-month-old infants, we try to show that foreign workers can present an immediate danger. The Tracheoesophageal fistula is a medical-surgical emergency that requires multidisciplinary management involving clinicians, radiologists, surgeons and endoscopists. Lack of adequate equipment can lead to death.
\end{abstract}

Keywords: Difficulty; Tracheoesophageal Fistula; Infant

\section{Introduction}

Foreign body inhalation is a frequent, poorly documented and multifactorial situation. It can be accidental or voluntary and especially common in children. In adults, it often occurs on a particular terrain, edentulous elderly subjects, patients with psychotic disorders or prisoners. Foreign corps may present an immediate danger, delayed during disposal or even during extraction. It is a medical-surgical emergency that requires multidisciplinary care involving clinicians, radiologists, surgeons and endoscopists. This observation relates to a case of o-tracheal fistula by accidental inhalation, in order to identify the diagnostic approach and the therapeutic difficulty in our environment often marked by the lack of adequate means of management.

\section{Observation}

This was a 16-month-old male infant who had been admitted for dyspnea, fecal vomiting (mouth and nostrils) and agitation after ingestion of a chicken bone one hour after the meal. On arrival, there was respiratory distress, hypotension 10/6, saturation at $80 \%$, normal temperature, weight of $20 \mathrm{~kg}$. The clinical examination noted a violent coughing, expelling coughing, cyanosis of the extremities, abdominal bloating and poor abdominal thoracic ampliation. At the auscultation there were pulmonary and abdominal tremors. It is concluded that there is a penetration syndrome. Imaging noted right lower lobar pneumonia by incomplete obstruction of the right strain bronchus in connection with a slender in traesophageal foreign body crossing the tracheal bifurcation: chicken bone, complicated bronchial compression with downstream pneumonia. We had undertaken resuscitation measures with monitoring. Mofenson's maneuver without success, brought back fecal content through nostrils and an increase in the abdominal cavity. Ventilation and intubation were impossible through the barrage of

Citation: Ngakani Offobo Silvère., et al. "Difficulty and Obstacle in the Management of an Tracheoesophageal Fistula by Accidental Inhalation of a Foreign Body (Chicken Bone), in a 16-month-old Infant at the Amissa Bongo Regional Hospital Center in Franceville". Acta Scientific Medical Sciences 6.3 (2022): $39-42$. 
the foreign body (chicken bone). Endoscopic extraction was indicated with an occlusive risk. The foreign body was not visible. We note the unavailability of endoscopic and emergency extraction equipment; hence the indication of medical evacuation. Evacuation to a reference structure was impossible. We see a gradual desaturation and an evolution towards sudden death.

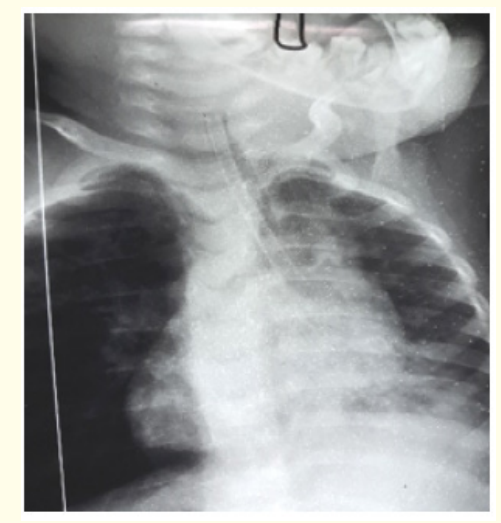

Photo 1: Slender intraesophageal foreign body crunching the tracheal bifurcation (image Offobo Silvere).

\section{Discussion}

In most statistics, peanuts account for more than $50 \%$ of foreign bodies inhaled in children [1-3]. Our case, this is chicken bone in a 16-month-old infant. In the United States, hot dogs, such as balloon fragments, are responsible for several deaths by asphyxiation [4]. In adults, food accounts for most inhaled bodies. Dental prostheses and fragments also remain prominent among this catalogue [5]. Inhalation of foreign bodies related to oral or maxillofacial surgery has been described [6], as well as the intra bronchial position of the esogastric tube. In the child, it is the little boy who pays the heaviest price (2/3 of the cases) [7]. In adults, the frequency of the accident increases with age and occurs especially from the seventh decade $[8,9]$. Metallic foreign bodies are often better tolerated by the bronchial mucosa than food foreign bodies. Among the latter, oilseeds are responsible fora neighborhood bronchial inflammation (peanut bronchitis) [10]. The most frequent localizations are laryngotracheo-bronchial according to different reviews of the literature [1,11-13]. In our case the chicken bone is located straddle between the esophagus and the tracheal bifurcation. Rarer symptoms may be observed (hemoptysis, pleurisy, lung abscesses or even pneumothorax or pneumo mediastinum) [14] [15]. Finally, a normal clinical examination does not in any way eliminate the presence of a foreign body. Any delay in diagnosis can be seriously prejudicial to the patient $[16,17]$. In some cases, chest computed tomography may be indicated [19] and magnetic resonance imaging could allow the visualization of fatty bodies in the peripheral bronchi $[20,21]$. The principle of the Heimlich maneuver consists in the creation of a brutal intra-tracheo bronchial hyperpressure [22]. In infants under one year of age, most authors advise against the Heimlich maneuver because of more frequent indulgences at this age [23]. In our case Mofenson's maneuver was unsuccessful. Direct tracheal puncture is the fastest rescue method [24]. Percutaneous cricothyroidotomy devices are not common or easy to use. Several kits are available on the market (Quick trach ${ }^{\circledR}$, Trachéoquick ${ }^{\circledR}$, Minitrach ${ }^{\circ}$ ). The success of the gesture depends above all on the experience of the operator [25]. Complications are not uncommon and can sometimes even worsen ventilatory situation [26]. Surgical cricothyroidotomy would be for some, the most satisfactory method in emergency situations [27]. Corticosteroid therapy can be prescribed by inhalation [28]; similarly, an adrenaline aerosol can be administered $\left(0.25 \%\right.$ adrenaline solution; $0.5-1 \mathrm{~mL} \cdot \mathrm{kg}^{-1}$ diluted in saline with oxygen as a carrier gas) [29]. Several authors combine a rigid tube bronchoscope and a fibroscope to locate and extract certain distorted foreign bodies [30]. Anesthesia for endoscopie laryngo-tracheo-bronchial is necessary [7,31,32]. It is necessary to have at its disposal a Fogarty probe to open up certain round foreign bodies, or even a Dormia type basket probe [33,34]. Some authors consider that the lesions are definitive beyond 30 days after the accident [35]. Finally, if endoscopic extraction of the foreign body does not appear possible (isolation, major bronchial lesions), the surgical indication should be discussed [36,37].

\section{Conclusion}

Foreign bodies of the airways and digestive tract remain a topical issue. In small children, the causes are multiple. Progress has also been marked by rapid diagnosis of the foreign body as soon as it is used by endoscopic examination. The diagnosis of tracheal fistula may be obvious but has been managed is limited. The remote health regions must strengthen the technical platform of endoscope and a multidisciplinary team of clinicians resuscitator, radiologist, surgeons, endoscopy.

\section{Conflicts and Interests}

No conflict and interests.

Citation: Ngakani Offobo Silvère., et al. "Difficulty and Obstacle in the Management of an Tracheoesophageal Fistula by Accidental Inhalation of a Foreign Body (Chicken Bone), in a 16-month-old Infant at the Amissa Bongo Regional Hospital Center in Franceville". Acta Scientific Medical Sciences 6.3 (2022): 39-42. 


\section{Bibliography}

1. François M., et al. "Endoscopy for the search for foreign bodies of the lower airways in children. About 668 cases". Annales D'oto-Laryngologie Et De Chirurgie Cervico Faciale 102 (1985): 433-441.

2. Piquet JJ., et al. "Epidemiology and prevention of bronchial foreign bodies”. Journal of Otolaryngology 29 (1980): 565-567.

3. Desnos J., et al. "Bronchial foreign bodies". Journal français d'oto-rhino-laryngologie 29 (1980): 651-653.

4. Harris CS., et al. "Childhood asphyxiation by food. A national analysis and overview". The Journal of the American Medical Association 251 (1984): 22231-22235.

5. Abdullah BJJ., et al. "Dental prosthesis ingested and impacted in the esophagus and orolaryngopharynx". Journal of Otolaryngology 27 (1998): 190-194.

6. Fields RT and Schow SR. "Aspiration and ingestion of foreign bodies in oral and maxillofacial surgery: a reviex of the literature and report of five cases". Journal of Oral and Maxillofacial Surgery 56 (1998): 1091-1098.

7. Lescanne E., et al. "Laryngo-tracheobronchial foreign bodies". Encyclo Med Chir ENT (1997): 20-730-A 10.

8. Mittleman RE and Wetli CV. "The fatal cafe coronary. Foreign body airway obstruction". The Journal of the American Medical Association 247 (1982): 1285-1288.

9. Limper AH and Prakash UB. "Tracheobronchial foreign bodies in adults". Annals of Internal Medicine 112 (1990): 604-609.

10. Atlas DH. "Cafe coronary from peanut butter". The New England Journal of Medicine 296 (1977): 399.

11. Wiseman NE. "The diagnosis of foreign body aspiration in childhood". Journal of Pediatric Surgery 19 (1984): 531-535.

12. Steen $\mathrm{KH}$ and Zimmermann TH. "Tracheobronchial aspiration of foreign bodies in children: a study of 94 cases". Laryngoscope 100 (1990): 525-530.

13. Mu L., et al. "Inhalation of foreign bodies in Chinese children: a review of 400 cases". Laryngoscope 101 (1991): 657-660.

14. Khiati M., et al. "Pulmonological aspects of the bronchial foreign body in children. Experience of 100 cases". Revue de Pneumologie Clinique 40 (1984): 221-226.
15. Newson TP., et al. "Tension pneumothorax secondary to grass head aspiration". Pediatric Emergency Care 14 (1998): 287289.

16. Messner AH. "Pittfalls in the diagnosis of aerodigestive tract foreign bodies". Clinical Pediatrics 37 (1998): 359-365.

17. Cohen SR. "Unusual presentations and problems created by mismanagement of foreign bodies in the aerodigestive tract of the pediatric patient". Annals of Otology, Rhinology, and Laryngology 90 (1981): 316-322.

18. Silva AB., et al. "Utility of conventional radiography in the diagnosis and management of pediatric airway foreign bodies". Annals of Otology, Rhinology, and Laryngology 107 (1998): 834-838.

19. Malis DJ and Hayes DK. "Retained bronchial foreign bodies: Is there a role for high-resolution computed tomography scan?". Otolaryngology-Head and Neck Surgery 112 (1995): 341-346.

20. Imaizumi H., et al. "Definitive diagnosis and location of peanuts in the airways using magnetic resonance imaging techniques". Annals of Emergency Medicine 6 (1994): 1379-1382.

21. Tashita H., et al. "Magnetic resonance imaging for early detection of bronchial foreign bodies". European Journal of Pediatrics 157 (1998): 442.

22. Heimlich HJ. "A life-saving maneuver to prevent food chocking". The Journal of The American Medical Association 234 (1975): 398.

23. Fink J and Klein. "Complications of the Heimlich maneuver". Journal of Pediatric Surgery 24 (1989): 486-487.

24. Aye LS. "Percutaneous transtracheal ventilation". Anesthesia and Analgesia 62 (1983): 619-623.

25. Esses BA and Jafek BW. "Cricothyroidotomy: a decade of experience in Denver". Annals of Otology, Rhinology, and Laryngology 96 (1987): 519-524.

26. Wain JC., et al. "Clinical experience with minitracheotomy". The Annals of Thoracic Surgery 49 (1990): 881-886.

27. Erlandson M., et al. "Cricothyroidotomy in the emergency department revisited". The Journal of Emergency Medicine 7 (1989): 115-118.

Citation: Ngakani Offobo Silvère., et al. "Difficulty and Obstacle in the Management of an Tracheoesophageal Fistula by Accidental Inhalation of a Foreign Body (Chicken Bone), in a 16-month-old Infant at the Amissa Bongo Regional Hospital Center in Franceville". Acta Scientific Medical Sciences 6.3 (2022): $39-42$. 
Difficulty and Obstacle in the Management of an Tracheoesophageal Fistula by Accidental Inhalation of a Foreign Body (Chicken Bone), in a 16-month-old Infant at the Amissa Bongo Regional Hospital Center in Franceville

28. Husby S., et al. "Treatment of croup with nebulised steroid: a double blind, placebo controlled study". Archives of Disease in Childhood 68 (1993): 352-355.

29. Ross Westley C., et al. "Nebulised racemic epinephrine by IPPB for the treatment of croup. A double blind study". American Journal of Diseases of Children 132 (1978): 484-487.

30. Ruegemer JL and Perkins JA. "Combined rigid and flexible endoscopic removal of a BB foreign body from a peripheral bronchus". International Journal of Pediatric Otorhinolaryngology 47 (1999): 77-80.

31. Coté CJ and Todres ID. "The pediatric airway". In: Coté CJ, Ryan JF, Todres ID, Goudsouzian NG, eds. A practice of anesthesia for infants and children. $2^{\text {nd }}$ Ed. Philadelphia: WB Saunders (1993): 55-83.

32. Brett CM., et al. "Eyes, ears, nose, throat, and dental surgery". In: Gregory GA, ed. Pediatric anesthesia. $3^{\text {rd }}$ Ed. New York: Churchill Livingstone (1994): 657-697.

33. Wiesel JM., et al. "Use of a fogarty catheter for bronchoscopic removal of a foreign body". Chest 81 (1982): 524.

34. Horowitz M., et al. "Endourologic removal of upper airway foreign objects”. Journal of Pediatric Surgery 31 (1996): 17271728.

35. Dutau G., et al. "Short- and medium-term respiratory sequelae of the bronchial etrangers". Revue des Maladies Respiratoires 9 (1981): 358-359.

36. Marks SC., et al. "Indications for open surgical removal of airway foreign bodies". Annals of Otology, Rhinology, and Laryngology 102 (1993): 690-694.

37. Gurpinar AN., et al. "Open surgical removal of tracheobronchial foreign bodies". Journal of Pediatric Surgery 33 (1998): 776-777.

\section{Assets from publication with us}

- Prompt Acknowledgement after receiving the article

- Thorough Double blinded peer review

- Rapid Publication

- Issue of Publication Certificate

- High visibility of your Published work

Website: www.actascientific.com/

Submit Article: www.actascientific.com/submission.php

Email us: editor@actascientific.com

Contact us: +919182824667

Citation: Ngakani Offobo Silvère., et al. "Difficulty and Obstacle in the Management of an Tracheoesophageal Fistula by Accidental Inhalation of a Foreign Body (Chicken Bone), in a 16-month-old Infant at the Amissa Bongo Regional Hospital Center in Franceville". Acta Scientific Medical Sciences 6.3 (2022): 